\title{
Determination of pararosaniline hydrochloride in workplace air
}

\author{
J. Kowalska (iD) A. Jeżewska
}

Received: 12 December 2018 / Accepted: 27 May 2019/Published online: 17 June 2019

(C) The Author(s) 2019

\begin{abstract}
Pararosaniline hydrochloride (CPR) is a dye used for colouring paper, leather and natural and artificial fibres. It is also used in analytical and microbiological laboratories. It is a carcinogenic substance of category $1 \mathrm{~B}$. In analytical chemistry, it is used for detecting the following among others: bromates, formaldehyde, ozone, sulphite and sulfur dioxide. CPR is a dye commonly used in microbiology for staining preparations, for staining bacteria, antibodies or other organisms. In Poland, about 800 employees were exposed to this substance. The lack of methods for the determination of pararosaniline hydrochloride in workplace air makes it impossible to assess the occupational exposure of workers to this substance. For this reason, a determination method has been developed, which allows for the determination of pararosaniline hydrochloride in the air. This method makes it possible to determine the concentration of CPR in the air at the workplace within the range from 0.002 to $0.04 \mathrm{mg} / \mathrm{m}^{3}$ (for an air sample of $120 \mathrm{~L}$ ). The method is based on the adsorption of pararosaniline hydrochloride present in the workplace air on a polypropylene filter, eluting the substance deposited on the filter with methanol and analysing the solution thus obtained using high-performance liquid chromatography with a diode array detector (wavelength of $544 \mathrm{~nm}$ ). Using an Ultra C18 (250 mm length)
\end{abstract}

J. Kowalska $(\bowtie) \cdot$ A. Jeżewska

Department of Chemical, Aerosol and Biological Hazards, Central Institute for Labour Protection - National Research Institute, Czerniakowska 16, 00-701 Warsaw, Poland

e-mail: jokow@ciop.pl chromatographic column at a temperature of $23{ }^{\circ} \mathrm{C}$ and the mobile phase of methanol:0.1\% phosphoric acid(V) $(95: 5, v / v)$ at flow rate of $0.6 \mathrm{~mL} / \mathrm{min}$ makes it possible to determine the content of pararosaniline hydrochloride in the presence of aniline, nitrobenzene and 4tolylamine. Limit of detection and limit of quantification were $0.17 \mathrm{ng} / \mathrm{mL}$ and $0.51 \mathrm{ng} / \mathrm{mL}$, respectively.

Keywords 4,4'-(4-iminocyclohexa-2,5dienylidenemethylene)dianiline hydrochloride $\cdot$ Basic Red 9 monohydrochloride · Pararosaniline hydrochloride - Diamant fuchsine - Carcinogens . Occupational exposure $\cdot$ Analysis of air . Chromatography $\cdot$ Validation

\section{Introduction}

Pararosaniline hydrochloride (CPR; CAS No. 569-61-9) also known as parafuchsine hydrochloride, C.I. basic red monohydrochloride, C.I. 42500, magenta 0, 4,4'-(4iminocyclohexa-2,5-dienylidenemethylene)dianiline hydrochloride or Basic Red 9 is a solid with a red colour in a green metallic sheen. It is slightly soluble in water and ether and soluble in ethanol, methanol, benzyl alcohol and ethylene glycol methyl ether (Duman et al. 2015; IARC 2012; HSDB 2018).

CPR belongs to the triarylmethane class dyes and is used for colouring various types of materials and products: paper, leather, textiles, glass, waxes and cosmetics as well as for the manufacture of inks and paints (Martins et al. 2006; Zargar et al. 2009; IARC 2010; 
Perdih and Perdih 2011; Nadaroglu et al. 2015; HSDB 2018).

In analytical chemistry, it is used for determining the following among others: bromates, formaldehyde, ozone, sulphite and sulfur dioxide (Miksch et al. 1981; Dasgupta 1981; Steiner et al. 1987; Romele 1998; Goyal 2001; Segundo and Rangel 2001; GonzálezRodríguez et al. 2002; McFeeters and Barish 2003; Simkhada et al. 2005; Li and Zhao 2006; Goyal 2006; Ćwikła-Bundyra 2012; Pundir and Rawal 2013; Almeida Jr et al. 2018).

CPR is a dye used in microbiology for staining preparations, inter alia, for staining bacteria, antibodies or other organisms in different types of tissues (Schrijver et al. 2000; Kiernan 2004). It is used to prepare the Schiff reagent required for the staining procedure of cytological and histological material (Lyon et al. 2002).

CPR is classified as a carcinogenic substance of category 1B (Carc. 1B) with an assigned hazard statement H350: May cause cancer (EC No. 1272/ 2008) because it may cause bladder cancer (Case and Pearson 1954; Piolatto et al. 1991; Bennett and Davis 2002; Pira et al. 2010; IARC 1993, 2010, 2012).

The routes of potential human exposure to CPR are dermal contact, inhalation and ingestion. Laboratory personnel who use and handle basic fuchsin dye might be exposed to Basic Red 9 monohydrochloride (HSDB 2018).

From the resources of the Central Register of Data on Exposure to Carcinogenic or Mutagenic Substances, Mixtures, Agents or Technological Processes, maintained by the Nofer Institute of Occupational Medicine, Łódź, Poland, it transpires that in Poland in 2016, 800 employees (including 702 women) in 98 enterprises were occupationally exposed to CPR. They were mainly employees of factory, healthcare, environmental protection and veterinary laboratories as well as universities, scientific institutes and others.

The value of maximum admissible concentration (MAC) for this substance in workplace air is not specified in Poland.

In the literature, there are no methods of pararosaniline hydrochloride determination in the workplace air, and only methods for determining CPR content in an aqueous solution (Zargar et al. 2009; Tokalioglu et al. 2015), in industrial wastewater (Moawed and Alqarni 2013), in textiles and in toys (Ma et al. 2010; Huang et al. 2005; Guo et al. 2018) are available. Its poor biodegradability and carcinogenicity properties were reasons for the research conducted into the disposal of pararosaniline hydrochloride from the environment, mainly from wastewater (Martins et al. 2006; Gupta et al. 2008; Duman et al. 2015; Torun and Şolpan 2015; Nadaroglu et al. 2015; Sivarajasekar et al. 2016; El Haddad 2018; Ning et al. 2018; Li et al. 2018; Zhou et al. 2018).

Different separation and detection methods are employed for the determination of CPR among other dyes. Arráez Román et al. (2005) applied the interfacing capillary electrophoresis and surface-enhanced resonance Raman spectroscopy for this purpose.

Ding et al. (2009) optimised liquid chromatography coupling with electrospray ionisation tandem mass spectrometry for simultaneous separation and identification of nine carcinogenic dyes (inter alia Basic Red 9) prohibited in textile materials.

The spectrophotometric method is most commonly used for the determination of pararosaniline hydrochloride (Martins et al. 2006; Gupta et al. 2008; Zargar et al. 2009; Moawed and Alqarni 2013; Duman et al. 2015; Tokalioglu et al. 2015; Zhou et al. 2018; El Haddad 2018). The optical absorption spectrum of pararosaniline hydrochloride showed a maximum absorption band at $546 \mathrm{~nm}$ for the aqueous solution (Guha and Mohan 2004; Lyon et al. 2002; Martins et al. 2006; Duman et al. 2015) and $560 \mathrm{~nm}$ in solutions of 1-butanol (Vinitha et al. 2007). Therefore, in order to calculate the concentrations of CPR in solutions, the absorbance is determined at an absorption wavelength of $540-554 \mathrm{~nm}$.

European standards recommend the determination of carcinogenic and allergenic dyes in dyed, printed or coated textile products (PN-EN ISO 16373-3 2014) and toys (PN-EN 71-11 2007) carried out by liquid chromatography coupled with UV/Vis spectrophotometric detection and mass spectrometry.

The standard PN-EN 16373-3 ( 2014) makes it possible to identify some carcinogenic dyestuffs in dyed, printed or coated textile goods. The standard describes analytical techniques applied to determine the content of eleven carcinogenic dyes: high-performance liquid chromatography-photodiode array detector (HPLCDAD) and high-performance liquid chromatographymass spectrometer (HPLC-MSD). Dyestuffs, isolated from a sample of textile material (using triethylamine/ methanol) in a multi-stage process, were dissolved in methanol finally. Quantification is executed by the method of HPLC-DAD. It is recommended that dyes be separated on Inertsil ODS-3 $(150 \times 3.0 \mathrm{~mm} ; 5 \mu \mathrm{m})$ column at a temperature of $45^{\circ} \mathrm{C}$ and with the gradient programmed mobile phase consisting of acetonitrile and 
ammonium acetate $(10 \mathrm{mMol} / \mathrm{L})$. The measuring can be conducted at the analytical wavelengths of 350,480 , 500, 510, 540 (for Basic Red 9) and $600 \mathrm{~nm}$. The concentration range of calibration solutions of dyes in methanol is from 1 to $100 \mu \mathrm{g} / \mathrm{L}$. When a large number of foreign substances are detected in extract, HPLC-MSD is recommended for identification and quantification.

An analytical method based on HPLC combined with ultraviolet-visible spectrometric detection (UV/Vis) and tandem mass spectrometry (MS-MS) has also been used by Ma et al. (2010) for the determination of sixteen carcinogenic and allergenic dyestuffs in toys. The separation was performed with Zorbax Extend C18 column (150 mm $\times 2.1 \mathrm{~mm} ; 5 \mu \mathrm{m})$ at a temperature of $25^{\circ} \mathrm{C}$ with a mobile phase of acetonitrile-tetrahydrofuran-citrate buffered tetrabutylammonium hydroxide mixture under gradient elution. Each dyestuff was detected and quantified at its respective maximum ultraviolet-visible absorption wavelength for optimum sensitivity (Basic Red 9; $540 \mathrm{~nm}$ ).

The presence of carcinogens in work environments poses a big problem for employers, not to mention the personnel exposed to them. The carcinogen and mutagen directive (Directive 2004/37/EC 2004) sets out the minimum standards for the protection of workers from occupational carcinogens. Employers' duties include the following: identifying carcinogenic and mutagenic substances and mixtures, assessing the risk to workers and regular monitoring of workers' exposure to determine any health risk and deciding the measures to be taken.

Screening measurements of the concentration of carcinogens are performed to obtain quantitative information on exposure levels. Such information shall be useful in identifying potential health risks and in assessing health risks.

Due to the occurrence of pararosaniline hydrochloride in the working environment in Poland and the classification of this substance as carcinogenic of category $1 \mathrm{~B}$ (Carc. 1B), it has become necessary to determine its concentrations in the workplace air at a sufficiently low level.

The aim of the research was to develop a method of collecting air samples at a workplace enabling sampling using an individual dosimetry method, where the sampler is placed in the worker's breathing zone, selecting the appropriate filter on which the test substance is retained, and a solvent, which quantitatively elutes the substance from the filter. The developed quantitative method will make it possible to determine the concentration of carcinogenic CPR in the workplace air, which in turn will allow the determination of exposure indicators and facilitate the assessment of occupational risks for workers.

\section{Materials and methods}

\section{Equipment}

The tests were carried out using a liquid chromatograph by Agilent Technologies (Waldbronn, Germany), series 1200 , with a diode array detector (DAD) coupled online. Samples were introduced using the autosampler G225890010 (Agilent Technologies). ChemStation software was used to control the process of determining and collecting data. For separating the analytes, an Ultra C18 chromatography column $(250 \times 4.6 \mathrm{~mm})$ with $d_{\mathrm{p}}=$ $5 \mu \mathrm{m}$, with a pre-column $(10 \times 4.0 \mathrm{~mm})$ (Restek, Bellefonte, PA, USA), was used. A Gilair 5 Aspirator (Sensidyne, Clearwater, FL, USA) for personal air sampling and a WL-2000 mechanical shaker (JWElectronic, Warsaw, Poland) to carry out CPR recovery from the filter were both applied.

Material and reagent

The following reagents were used in the tests: pararosaniline hydrochloride (CPR) from Merck (Darmstadt, Germany), aniline, nitrobenzene (Sigma-Aldrich, Steinheim, Germany), methanol (J. T. Baker, Deventer, the Netherlands), phosphoric acid(V), 4-tolylamine (POCh, Gliwice, Poland) and high-purity water obtained from the Milli-Q apparatus (Millipore, Bedford, MA, USA). Reagents of HPLC grade were used during the tests.

Materials used were the following: glass fibre filters, GF/A with a diameter of $25 \mathrm{~mm}$ by Whatman (Maidstone, UK), filters made of poly(propylene), FIPRO with a diameter of $25 \mathrm{~mm}$ (Textile Research Institute, Łódź, Poland), poly(tetrafluoroethylene) filters, PTFE with a diameter of $25 \mathrm{~mm}$ (SKC, Pittsburgh, PA, USA), poly(vinyl chloride) filters and PVC with a diameter of 25 mm (SKC, Pittsburgh, PA, USA).

\section{Methodology}

\section{Sample preparation}

Air samples containing CPR $(120 \mathrm{~L})$ were collected on filters. Two millilitres of methanol was used for recovery of CPR deposited on the filter, and the contents were shaken for $30 \mathrm{~min}$. The solution from above the filter was then determined by means of chromatography using an Ultra C18 column for HPLC with a precolumn. 


\section{Chromatographic conditions}

The temperature of the Ultra $\mathrm{C} 18$ column was $23{ }^{\circ} \mathrm{C}$. The mobile phase flow rate was $0.6 \mathrm{~mL} / \mathrm{min}$. As the mobile phase, methanol:0.1\% phosphoric acid(V) (95:5, $v / v$ ) was used. The volume of the sample to be dispensed was $10 \mu \mathrm{L}$. A DAD detector was used for detection. The analytical wavelength $\lambda$ of the DAD detector was 544 $\mathrm{nm}$. These conditions enabled the determination of pararosaniline hydrochloride in the presence of aniline, nitrobenzene and 4-tolylamine, i.e. substances that may co-exist with CPR in the work environment. These substances do not interfere with the CPR determination at the analytical wavelength of $544 \mathrm{~nm}$ (Fig. 1).

\section{Examination of recovery}

In order to determine the degree of CPR recovery from the FIPRO filter, the following activities were carried out: $0.24 \mu \mathrm{g}$ of pararosaniline hydrochloride (dosing 10 $\mu \mathrm{L}$ of a CPR solution in methanol at $24 \mu \mathrm{g} / \mathrm{mL}$ ), as well as $2.4 \mu \mathrm{g}$ and $4.8 \mu \mathrm{g}$ of CPR, was applied onto filters $(6$ pieces each) by subsequent dosing of $10 \mu \mathrm{L}$ and $20 \mu \mathrm{L}$ of a CPR solution in methanol at $240 \mu \mathrm{g} / \mathrm{mL}$. The filters were then dried and $120 \mathrm{~L}$ of air was passed through them. CPR recovery was carried out with methanol (2 $\mathrm{mL}$ ), shaking the contents for $30 \mathrm{~min}$. Solutions from above the filters were determined by means of chromatography. Pararosaniline hydrochloride determination was also carried out in comparative solutions made in the same way but without a filter. A method is considered accurate if the average recovery obtained from a series of measurements is between 97 and $103 \%$.

\section{Calibration and precision}

Calibration assays were performed for six CPR standard solutions in methanol in the concentration range from 0.12 to $2.4 \mu \mathrm{g} / \mathrm{mL}$. Three series of calibration solutions were made, which were subjected to chromatographic analysis. Ten microlitres of standard solutions with increasing concentrations was introduced into the chromatograph. The analytical precision of the calibration determinations was evaluated on the basis of the analysis of three series of eight working solutions with CPR concentrations successively at 0.12 (first series), 1.2 (second series) and $2.4 \mu \mathrm{g} /$ $\mathrm{mL}$ (third series). For the following analysis, each of three series of standard solutions, standard deviations and the coefficients of variation was calculated.

\section{Method validation}

Validation parameters were determined in accordance with the requirements contained in the European standard PN-EN 482 ( 2016). The overall approach, including both sampling and analytical methods, was tested by determining the recovery, linearity, sensitivity, precision and expanded uncertainty. The limit of detection and the limit of quantification are based on the results of the analysis of ten independent peak area measurements

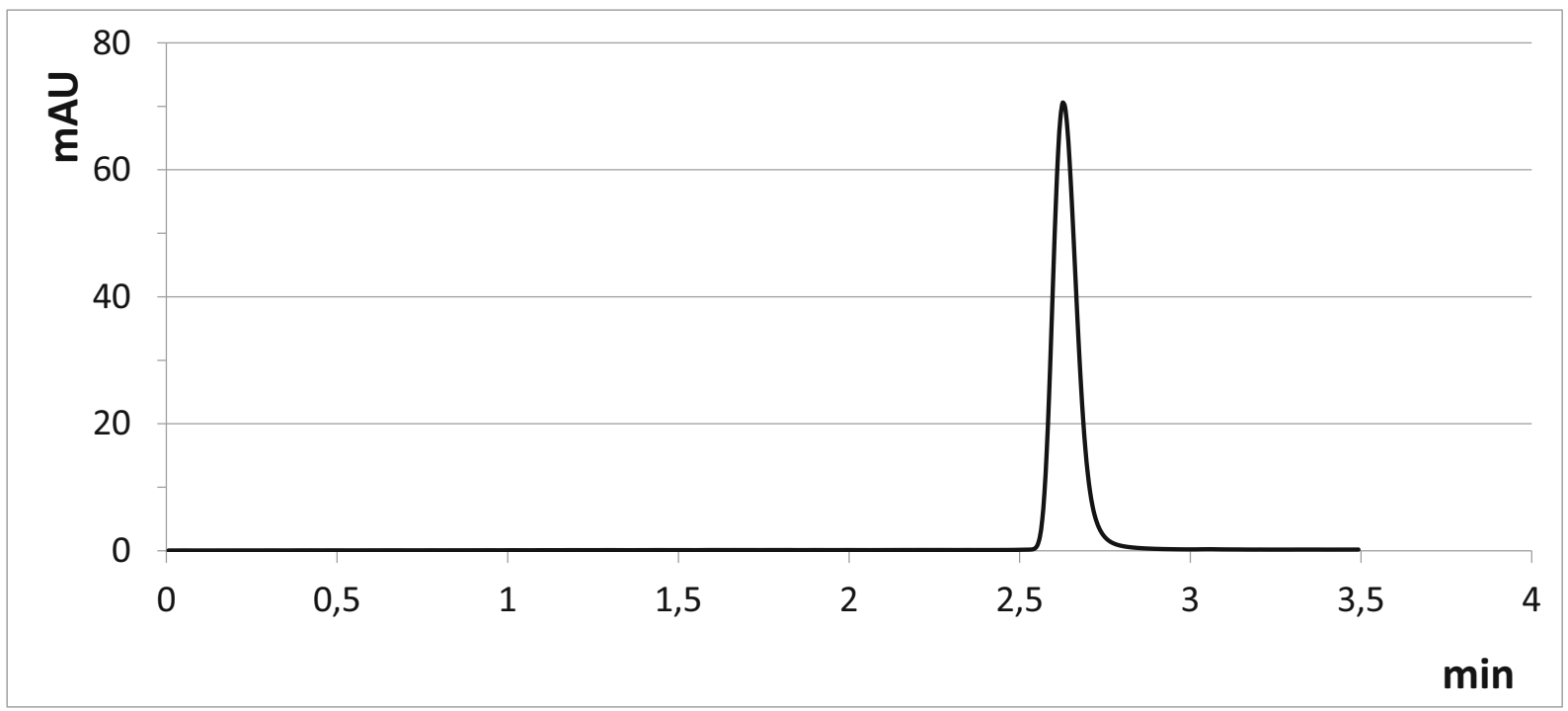

Fig. 1 Chromatogram of the CPR standard solution in methanol 
with the CPR retention time for three independently prepared blank samples. To calculate the limit of detection (LOD), the following dependence was used:

$\mathrm{LOD}=\frac{3.3 \cdot s_{o}}{b}$

where $b$ is the coefficient of the directional calibration line (calibration coefficient) obtained when determining linearity, and $s_{o}$ is the standard deviation of results obtained for a series of blank samples.

The LOQ value was calculated as a multiple of the determined LOD value: $L O Q=3$ LOD.

The total analytical precision $\left(V_{c}\right)$ which includes laboratory precision for the measurement range and sampling method was determined from the following formula:

$V_{c}=\sqrt{V_{z}^{2}+V_{p}^{2}}$

where $V_{p}$ is the precision of the sampling device $\left(V_{p}= \pm\right.$ $5 \%$ ), and $V_{z}$ is the average precision of three levels within the range, calculated from the formula:

$V_{z}=\sqrt{\frac{\sum\left(n_{j}-1\right) \cdot V_{i}^{2}}{\sum\left(n_{j}-1\right)}}$

where $n_{j}$ is the number of repeated samples $\left(n_{j}=8\right)$, and $V_{i}$ is the variation coefficient for the concentration level.

The total analytical precision value $\left(V_{c}\right)$ is taken into account in the calculation of combined standard uncertainty. The expanded uncertainty is obtained by multiplying the combined standard uncertainty with a coverage factor of $2(p=0.95)$.

\section{Results and discussion}

The tests were carried out to determine the conditions for collecting air samples containing pararosaniline hydrochloride to ensure the quantitative separation of substances from the workplace air. Typically, the particles, which have been collected into a filter, an adsorbent, or a similar system, are extracted with a suitable solvent and subsequently analysed. Pararosaniline hydrochloride is a solid under normal conditions; therefore, filters must be used to isolate it from the air. The following filters were used for the tests: PVC, PTFE, GF/A and FIPRO, which can be easily placed in the worker's breathing zone as per the principles of individual dosimetry (PN-
Z-04-008-7). Using the individual dosimetry method, the most reliable results of occupational exposure assessment are obtained.

Preliminary investigations of CPR recovery from filters

Initial investigations of the degree of $\mathrm{CPR}$ recovery from the filters (PVC, PTFE, FIPRO and GF/A) were tested as follows: $100 \mu \mathrm{L}$ of a CPR solution in methanol at $24 \mu \mathrm{g} / \mathrm{mL}$ was applied onto filters (3 pieces each) and allowed to dry. The dried filters were extracted with 2 $\mathrm{mL}$ of methanol. After shaking (30 $\mathrm{min}$ ), the solutions from above the filter were analysed chromatographically under the conditions given above. Comparable values of recovery were obtained for all the tested filters (about 98\%) (Table 1). Due to the lower cost of the GF/A and FIPRO filters in comparison with the others, these filters were chosen for further research.

Investigation of air sampling conditions

In order to determine the conditions of air sampling and the selection of one type of filter, a system consisting of two GF/A filters connected in a series and a suction pump with a constant volume of air flow controlled by a rotameter and an identical set consisting of two FIPRO filters were assembled. In each set, the first filter contained the test substance (12 $\mu \mathrm{g}$ of substance) and

Table 1 Comparison of filters (CPR recovery from filters with methanol). Ultra C18 column, DAD detector $(\lambda=544 \mathrm{~nm})$

\begin{tabular}{lllll}
\hline $\begin{array}{l}\text { Type } \\
\text { of filter }\end{array}$ & $\begin{array}{l}\text { Average area } \\
\text { of CPR peaks } \\
\text { from recovery } \\
\text { solutions }\end{array}$ & $\begin{array}{l}\text { Average area } \\
\text { of peaks } \\
\text { from } \\
\text { comparative } \\
\text { solutions }\end{array}$ & $\begin{array}{l}\text { Recovery } \\
(\%)\end{array}$ & $\begin{array}{l}\text { Average } \\
\text { recovery } \\
(\%)\end{array}$ \\
\hline PVC & 329.9 & 335.8 & 98 & 98 \\
& 330.2 & & 98 & \\
& 331.15 & & 99 & \\
PTFE & 327.7 & & 98 & 97 \\
& 330.1 & & 98 & \\
& 322.7 & & 96 & 98 \\
FIPRO & 323.5 & & 96 & \\
& 330.2 & & 98 & \\
& 329.65 & & 98 & \\
GF/A & 328.0 & & 98 & \\
& 327.3 & & 98 & \\
\hline
\end{tabular}


the second filter was clean, i.e. the so-called control one. One hundred twenty litres of air was passed through the system with a constant flow rate of $120 \mathrm{~L} / \mathrm{h}, 60 \mathrm{~L} / \mathrm{h}$ and $20 \mathrm{~L} / \mathrm{h}$; after which, the filters were left in the desiccator until the following day. The solution obtained after the extraction of CPR from the filters ( $2 \mathrm{~mL}$ of methanol) was analysed by means of chromatography. The results are presented in Table 2. The results obtained indicate the retention of CPR on the first filter. The recovery of substances from the FIPRO filters was higher than that from the GF/A filters. For this reason, the FIPRO filters were selected for further investigations, with just one filter being sufficient, as the investigated substance does not pass to the second filter. On the basis of the results obtained, the method of collecting air samples containing CPR was determined: $120 \mathrm{~L}$ of air being tested is passed through a polypropylene filter with a volume stream not higher than $120 \mathrm{~L} / \mathrm{h}$. Such a procedure allows for collecting one air sample over $6 \mathrm{~h}$ in the worker's breathing zone, in accordance with the principles of individual dosimetry included in the Polish standard PN-Z-04008-7 (2002).

\section{Examination of recovery}

The recovery was calculated by comparing the analytical results for the extracted samples in three concentrations with the non-extracted standards (assumed to be $100 \%$ recovery). Recovery of the analyte should be between 95 and $105 \%$. The results are presented in Table 3. The average recovery rate was $98 \%$. The relative standard deviation was $<10 \%$ for all values.

Table 2 Exemplary CPR adsorption studies on FIPRO and GF/A filters. Ultra C18 column, DAD detector $(\lambda=544 \mathrm{~nm})$

\begin{tabular}{llll}
\hline Type of filter & $\begin{array}{l}\text { Flowrate } \\
\text { of air }(\mathrm{L} / \mathrm{h})\end{array}$ & $\begin{array}{l}\text { Area of CPR peaks in recovery } \\
\text { solutions }\end{array}$ \\
\cline { 3 - 4 } & & 1 st filter & 2nd filter \\
\hline FIPRO & 0 & 1,830 & - \\
FIPRO & 120 & 1,750 & - \\
FIPRO & 60 & 1,722 & - \\
FIPRO & 20 & 1,735 & - \\
GF/A & 0 & 1,508 & - \\
GF/A & 120 & 1,476 & - \\
GF/A & 60 & 1,308 & - \\
GF/A & 20 & 1,240 & - \\
\hline
\end{tabular}

Table 3 Determination of CPR recovery rate from the FIPRO filter. Ultra C18 column, DAD detector $(\lambda=544 \mathrm{~nm})$

\begin{tabular}{lllll}
\hline $\begin{array}{l}\text { CPR mass } \\
\text { applied } \\
\text { onto the } \\
\text { filter }(\mu \mathrm{g})\end{array}$ & $\begin{array}{l}\text { Average area } \\
\text { of peaks in } \\
\text { recovery } \\
\text { solutions }\end{array}$ & $\begin{array}{l}\text { Average area } \\
\text { of peaks in } \\
\text { comparative } \\
\text { solutions }\end{array}$ & $\begin{array}{l}\text { Relative } \\
\text { standard } \\
\text { deviation } \\
(\%)\end{array}$ & $\begin{array}{l}\text { Average } \\
\text { recovery } \\
(\%)\end{array}$ \\
\hline 0.24 & 32.2 & 33.0 & 2.2 & 98 \\
2.4 & 323.0 & 330.6 & 0.36 & 98 \\
4.8 & 653.9 & 664.0 & 0.57 & 98 \\
\hline
\end{tabular}

\section{Calibration and precision}

The calibration curve consisted of six calibration points using replicated samples. The area peak of CPR vs. the concentration was plotted and produced a linear curve for the concentration range used $(0.12-2.2 \mu \mathrm{g} / \mathrm{mL})$ with a correlation coefficient of 1 . A typical equation for the calibration curve was $y=278 x+0.13$ (Table 4) where $y$ represents the peak area of CPR and $x$ represents the CPR concentration in microgrammes per millilitre.

The precision of the calibration determinations was evaluated on the basis of the analysis of three series $(0.12,1.2$ and $2.4 \mu \mathrm{g} / \mathrm{mL})$ of eight CPR standard solutions in methanol. The coefficients of variation for successive concentration levels are 1.79, 0.41 and $0.74 \%$, respectively. The total analytical precision determined (according to formula 2) was $5.13 \%$.

Validation results

Validation parameters were determined in accordance with good laboratory practise and the requirements contained in the European standard PN-EN 482 (2016). The validation data obtained on the basis of

Table 4 Calibration parameters for the three measurement series

\begin{tabular}{|c|c|c|c|}
\hline \multirow[t]{2}{*}{ Parameter } & \multicolumn{3}{|c|}{ Measuring series } \\
\hline & $\mathrm{I}$ & II & III \\
\hline $\begin{array}{l}\text { Calibration curve } \\
\qquad(y=b x+a)\end{array}$ & $\begin{array}{c}y=279 x- \\
0.23\end{array}$ & $\begin{array}{c}y=277 x+ \\
0.14\end{array}$ & $\begin{array}{c}y=277 x+ \\
0.50\end{array}$ \\
\hline Correlation coefficient, $r$ & 1 & 1 & 1 \\
\hline $\begin{array}{l}\text { Average value of the } \\
\text { calibration coefficient }\end{array}$ & 278 & & \\
\hline $\begin{array}{l}\text { Coefficient of variation } \\
\text { of the calibration } \\
\text { coefficient }(\%)\end{array}$ & 0.49 & & \\
\hline
\end{tabular}


Table 5 Validation data for the determination method of pararosaniline hydrochloride

\begin{tabular}{ll}
\hline Parameter & Value \\
\hline Measuring range & $0.002 \div 0.04 \mathrm{mg} / \mathrm{m}^{3}$ \\
Amount of air collected & $120 \mathrm{~L}$ \\
Lineal concentration range & $0.12 \div 2.4 \mu \mathrm{g} / \mathrm{mL}$ \\
Limit of detection (LOD) & $0.17 \mathrm{ng} / \mathrm{mL}$ \\
Limit of quantification (LOQ) & $0.51 \mathrm{ng} / \mathrm{mL}$ \\
Overall precision of the test & $5.1 \%$ \\
Expanded uncertainty & $23 \%$ \\
\hline
\end{tabular}

the results of the tests performed are presented in Table 5 and are in agreement with EN 482 requirements which are specific for working environment. The limit of quantification was $0.51 \mathrm{ng} / \mathrm{mL}$. This corresponds to $0.001 \mu \mathrm{g}$ per sample. The relative quantification limit was $8.5 \cdot 10^{-6} \mathrm{mg} / \mathrm{m}^{3}$ for an air sample volume of $120 \mathrm{~L}$. The expanded uncertainty for those methods was acceptable and is equal to $23 \%$.

\section{Conclusion}

As a result of the research conducted, a method for the determination of pararosaniline hydrochloride in the workplace air using high-performance liquid chromatography with a diode array detector was developed. The method involves passing the tested air containing pararosaniline hydrochloride through a polypropylene filter, extracting the substance from the filter with methanol and chromatographic analysis of thus obtained solution using the Ultra C18 column $(250 \times 4.6 \mathrm{~mm} ; 5$ $\mu \mathrm{m})$. The method was validated in accordance with the European standard PN-EN 482. Good validation results were obtained. The developed method enables the determination of pararosaniline hydrochloride in the air of the work environment in the concentration range of 0.002 to $0.04 \mathrm{mg} / \mathrm{m}^{3}$ and can be used to assess occupational exposure to this substance.

Acknowledgements This article is based on the results of research task carried out within the scope of the fourth stage of the National Programme "Improvement of safety and working conditions" partly supported in 2017-2019 — within the scope of research and development — by the Ministry of Science and Higher Education/National Centre for Research and Development. The Central Institute for Labour Protection - National Research Institute (CIOP-PIB) is the programme's main coordinator.
Open Access This article is distributed under the terms of the Creative Commons Attribution 4.0 International License (http:// creativecommons.org/licenses/by/4.0/), which permits unrestricted use, distribution, and reproduction in any medium, provided you give appropriate credit to the original author(s) and the source, provide a link to the Creative Commons license, and indicate if changes were made.

\section{References}

Almeida, P. L., Jr., Figueiredo do Bonfim, T. H., Cunha, F. A. S., Lima, K. M. G., Aquino, J. S., \& Almeida, L. F. (2018). A rapid, sensitive and green analytical method for the determination of sulfite in vinegars using pararosaniline reaction with image detection. Analytical Methods, 10, 448-458. https://doi.org/10.1039/C7AY02155K.

Arráez Román, D., Efremov, E., Ariese, F., Segura Carretero, A., \& Gooijer, C. (2005). Interfacing capillary electrophoresis and surface-enhanced resonance Raman spectroscopy for the determination of dye compounds. Analytical and Bioanalytical Chemistry, 382(1), 180-185. https://doi. org/10.1007/s00216-005-3164-x.

Bennett, L. M., \& Davis, B. J. (2002). Identification of mammary carcinogens in rodent bioassays. Environmental and Molecular Mutagenesis, 39(2-3), 150-157. https://doi. org/10.1002/em.10068.

Case, R. A., \& Pearson, J. T. (1954). Tumours of the urinary bladder in workmen engaged in the manufacture and use of certain dyestuff intermediates in the British chemical industry. II. Further consideration of the role of aniline and of the manufacture of auramine and magenta (fuchsine) as possible causative agents. British Journal of Industrial Medicine, 11, 213-216.

Ćwikła-Bundyra, W. (2012). Oznaczanie ozonu. Urządzenia wzbudzające tlen. Laboratorium, 3-4, 41-42.

Dasgupta, P. K. (1981). Determination of atmospheric sulfur dioxide without tetrachloromercurate(II): Further refinements of a pararosaniline method and field application. Journal of the Air Pollution Control Association, 31(7), 779-782.

Ding, Y., Sun, C., \& Xu, X. (2009). Simultaneous identification of nine carcinogenic dyes from textiles by liquid chromatography/electrospray ionization mass spectrometry via negative/positive ion switching mode. European Journal of Mass Spectrometry, 15(6), 705-713. https://doi. org/10.1255/ejms.1032.

Directive 2004/37/EC of the European Parliament and of the Council of 29 April 2004 on the protection of workers from the risks related to exposure to carcinogens or mutagens at work (Sixth individual Directive within the meaning of Article 16(1) of Council Directive 89/391/EEC) (codified version) (Text with EEA relevance) (OJ L 158, 30.4.2004, p. 50)

Duman, O., Tunç, S., \& Polat, T. G. (2015). Adsorptive removal of triarylmethane dye (Basic Red 9) from aqueous solution by sepiolite as effective and low-cost adsorbent. Microporous and Mesoporous Materials, 210, 176-184.

El Haddad, M. (2018). Removal of basic fuchsin dye from water using mussel shell biomass waste as an adsorbent: 
Equilibrium, kinetics, and thermodynamics. J. Taibah Univ. Sci., 10, 664-674.

González-Rodríguez, J., Pérez-Juan, P., \& Luque de Castro, M. (2002). Sequential spectrophotometric determination of methanol and iron in vinegar by a flow injection-pervaporation method. Analytical and Bioanalytical Chemistry, 374, 120125. https://doi.org/10.1007/s00216-002-1432-6.

Goyal, S. K. (2001). Use of rosaniline hydrochloride dye for atmospheric SO2 determination and method sensitivity analysis. Journal of Environmental Monitoring, 3, 666-670. https://doi.org/10.1039/B106209N.

Goyal, S. K. (2006). Effect of reagent (dye) addition in wet chemical method of sulfur dioxide determination in ambient air. Environmental Monitoring and Assessment, 120, 461476. https://doi.org/10.1007/s10661-005-9073-9.

Guha, S., \& Mohan, H. (2004). Redox reactions of basic fuchsin in homogeneous aqueous media. Research on Chemical Intermediates, 30, 637-646. https://doi.org/10.1163 $/ 1568567041570302$.

Guo, X., Bai, H., Lv, Y., Xi, G., Li, J., Ma, X., Ren, Y., Ouyang, Z., \& Ma, Q. (2018). Rapid identification of regulated organic chemical compounds in toys using ambient ionization and a miniature mass spectrometry system. Talanta, 180, 182-192. https://doi.org/10.1016/j.talanta.2017.12.050.

Gupta, V. K., Mittal, A., Gajbe, V., \& Mittal, J. (2008). Adsorption of basic fuchsin using waste materials - bottom ash and deoiled soya-as adsorbents. Journal of Colloid and Interface Science, 319, 30-39. https://doi.org/10.1016/j. jcis.2007.09.091.

HSDB. 2018. Hazardous Substances Data Bank. National Library of Medicine. C.I. BASIC RED 9. https://toxnet.nlm.nih. gov/cgi-bin/sis/search2/f?./temp/ GPb7wR:2. Accessed: 24 August 2018.

Huang, M., Russo, R., Fookes, B. G., \& Sigman, M. E. (2005). Analysis of fiber dyes by liquid chromatography mass spectrometry (LC-MS) with electrospray ionization: Discriminating between dyes with indistinguishable UVvisible absorption spectra. Journal of Forensic Sciences, 50, 526-534. https://doi.org/10.1520/JFS2004223.

IARC. (1993). Magenta and C.I. basic red. In Occupational exposures of hairdressers and barbers and personal use of hair colourants; some hair dyes, cosmetic colourants, industrial dyestuffs and aromatic amines. IARC Monographs on the Evaluation of the Carcinogenic Risk of Chemicals to Humans, 57, 215-234.

IARC. (2010). Magenta and magenta production. In: Some aromatic amines, organic dyes, and related exposures. IARC Monographs on the Evaluation of Carcinogenic Risks to Humans, 99, 1-678.

IARC. (2012). Magenta and magenta production. In: Chemical agents and related occupations. A review of human carcinogens. IARC Monographs on the Evaluation of Carcinogenic Risks to Humans, 100F, 105-110.

Kiernan, J. (2004). Hexazonium pararosaniline as a fixative for animal tissues. Biotechnic \& Histochemistry, 79(5-6), 203210. https://doi.org/10.1080/10520290400018005.

Li, Y., \& Zhao, M. (2006). Simple methods for rapid determination of sulfite in food products. Food Control, 17, 975-980. https://doi.org/10.1016/j.foodcont.2005.07.008.

Li, C., He, Y., Zhou, L., Xu, T., Hu, J., Peng, C., \& Liu, H. (2018). Fast adsorption of methylene blue, basic fuchsin, and malachite green by a novel sulfonic-grafted triptycene-based porous organic polymer. RSC Advances, 8, 41986-41993. https://doi.org/10.1039/c8ra09012b.

Lyon, H. O., Schulte, E. K., Prento, P., Barer, M. R., \& Béné, M.C. (2002). Standardized staining methods: FeulgenRossenbeck reaction for desoxyribonucleic acid and periodic acid-Schiff (PAS) procedure. Biotechnic \& Histochemistry, 77(3), 121-125. https://doi.org/10.1080/bih.77.3.121.125.

Ma, Q., Bai, H., Zhang, Q., Ma, W., Xi, H., Zhou, X., \& Wang, C. (2010). Determination of carcinogenic and allergenic dyestuffs in toys by LC coupled to UV/Vis spectrometry and tandem mass spectrometry. Chroma, 72, 85-93. https://doi. org/10.1365/s10337-010-1634-6.

Martins, A. O., Canalli, V. M., Azevedo, C. M. N., \& Pires, M. (2006). Degradation of pararosaniline (C.I. Basic Red 9 monohydrochloride) dye by ozonation and sonolysis. Dyes and Pigments, 68, 227-234.

McFeeters, R. F., \& Barish, A. O. (2003). Sulfite analysis of fruits and vegetables by high-performance liquid chromatography (HPLC) with ultraviolet spectrophotometric detection. Journal of Agricultural and Food Chemistry, 51, 15131517. https://doi.org/10.1021/jf025693c.

Miksch, R. R., Anthon, D. W., Fanning, L. Z., Hollowell, C. D., Kenneth, R., \& Glanville, J. (1981). Modified pararosaniline method for the determination of formaldehyde in air. Analytical Chemistry, 53(13), 2118-2123.

Moawed, E. A., \& Alqarni, Y. (2013). Determination of azine and triphenyl methane dye in wastewater using polyurethane foam functionalized with tannic acid. Sample Preparation, 1, 18-27. https://doi.org/10.2478/sampre-2013-0003.

Nadaroglu, H., Alayli, A., \& Celebi, N. (2015). Removal of Basic Red 9 (BR9) in aqueous solution by using silica with nanomagnetite by enzymatic with Fenton process. International Journal of Environmental Research, 9(3), 991-1000.

Ning, J., Wang, M., Luo, X., Hu, Q., Hou, R., Chen, W., Chen, D., Wang, J., \& Liu, J. (2018). SiO2 stabilized magnetic nanoparticles as a highly effective catalyst for the degradation of basic fuchsin in industrial dye wastewaters. Molecules., 23(10), 2573.

Perdih, F., \& Perdih, A. (2011). Lignin selective dyes: quantummechanical study of their characteristics. Cellulose, 18, 1139-1150. https://doi.org/10.1007/s10570-011-9558-3.

Piolatto, G., Negri, E., LaVecchia, C., Pira, E., Decarli, A., \& Peto, J. (1991). Bladder cancer mortality of workers exposed to aromatic amines: An updated analysis. British Journal of Cancer, 63, 457-459.

Pira, E., Piolatto, G., Negri, E., Romano, C., Boffetta, P., Lipworth, L., McLaughlin, J. K., \& La Vecchia, C. (2010). Bladder cancer mortality of workers exposed to aromatic amines: A 58-year follow-up. Journal of the National Cancer Institute, 102, 1096-1099.

PN-EN 482+A1:2016 Workplace exposure - General requirements for the performance of procedures for the measurement of chemical agents. Polish Committee for Standardization, Warsaw 2016.

PN-EN 71-11:2007 Safety of toys - Part 11: Organic chemical compounds - Methods of analysis. Polish Committee for Standardization, Warsaw 2007.

PN-EN ISO 16373-3:2014 Textiles - Dyestuffs - Part 3: Method for determination of certain carcinogenic dyestuffs (method 
using triethylamine/methanol). Polish Committee for Standardization, Warsaw 2016.

PN-Z-04008-7:2002 Air purity protection - Sampling methods Principles of air sampling in work place and interpretation of results. Polish Committee for Standardization, Warsaw 2002.

Pundir, C. S., \& Rawal, R. (2013). Determination of sulfite with emphasis on biosensing methods: A review. Analytical and Bioanalytical Chemistry, 405, 3049-3062. https://doi. org/10.1007/s00216-013-6753-0.

Regulation (EC) No 1272/2008 2008 of the European Parliament and of the Council of 16 December 2008 on classification, labelling and packaging of substances and mixtures, amending and repealing Directives 67/548/EEC and 1999/45/EC, and amending Regulation (EC) No 1907/2006. EU OJ L 353, 31.12.2008, p. 1-1355.

Romele, L. (1998). Spectrophotometric determination of low levels of bromate in drinking water after reaction with fuchsin. Analyst, 123, 291-294. https://doi.org/10.1039/A706130G.

Schrijver, I. A., Melief, M., Meurs, M., Companjen, A. R., \& Laman, J. D. (2000). Pararosaniline fixation for detection of co-stimulatory molecules, cytokines, and specific antibody. Journal of Histochemistry and Cytochemistry, 48, 95-104.

Segundo, M. A., \& Rangel, A. O. S. S. (2001). A gas diffusion sequential injection system for the determination of sulphur dioxide in wines. Analytica Chimica Acta, 427, 279-286. https://doi.org/10.1016/S0003-2670(00)01197-1.

Simkhada, K., Murthy, K. V., \& Khanal, S. N. (2005). Assessment of ambient air quality in Bishnumati corridor, Kathmandu metropolis. International journal of Environmental Science and Technology, 2, 217-222. https://doi.org/10.1007 /BF03325878.

Sivarajasekar, N., Ramasubbu, S., Prakash Maran, J., \& Priya, B. (2016). Cationic dyes sequestration from aqueous phase using biosurfactant based reverse micelles. In I. Regupathi, K. V. Shetty, \& M. Thanabalan (Eds.), Recent advances in chemical engineering. Singapore: Springer. https://doi. org/10.1007/978-981-10-1633-2_8.

Steiner, C., Tottoli, M., \& Reber, H. (1987). Determination of formaldehyde concentration in a low-pressure sterilizer. Zentralblatt für Bakteriologie, Mikrobiologie und Hygiene. Serie B, 184(2), 122-145.

Tokalioglu, S., Yavuz, E., Aslantas, A., Sahan, H., Taskin, F., \& Patat, S. (2015). Spectrophotometric determination of basic fuchsin from various water samples after vortex assisted solid phase extraction using reduced graphene oxide as an adsorbent. Spectrochimica Acta A, 149, 378-384.

Torun, M., \& Șolpan, D. (2015). (2015) The removal of cationic dyes from aqueous solutions by using poly(Nvinylpyrrolidone-co-methacrylic acid) hydrogel adsorbents. Effects of $\mathrm{pH}$ and composition on adsorption. Fibers Polym, 16, 735-743. https://doi.org/10.1007/s12221-015-0735-0.

Vinitha, G., Ramalingam, A., \& Palanisamy, P. K. (2007). Nonlinear studies of pararosaniline dye in liquid and solid media. Spectrochimica Acta Part A: Molecular and Biomolecular Spectroscopy, 68(1), 1-5. https://doi. org/10.1016/j.saa.2006.10.042.

Zargar, B., Parham, H., \& Hatamie, A. (2009). Modified iron oxide nanoparticles as solid phase extractor for spectrophotometric determination and separation of basic fuchsin. Talanta, 77, 1328-1331. https://doi.org/10.1016/j. talanta.2008.09.011.

Zhou, Y., Yao, S., Ma, Y., Li, G., Huo, Q., \& Liu, Y. (2018). An anionic single-walled metal-organic nanotube with an armchair $(3,3)$ topology as an extremely smart adsorbent for the effective and selective adsorption of cationic carcinogenic dyes. Chemical Communications, 54(24), 3006-3009. https://doi.org/10.1039/c8cc00542g.

Publisher's note Springer Nature remains neutral with regard to jurisdictional claims in published maps and institutional affiliations. 